\title{
Towards bottom-up nanopatterning of Prussian blue analogues
}

\author{
Virgile Trannoy ${ }^{1}$, Marco Faustini ${ }^{2}$, David Grosso ${ }^{2}$, Sandra Mazerat ${ }^{1}$, François Brisset ${ }^{1}$, \\ Alexandre Dazzi ${ }^{3}$ and Anne Bleuzen*1
}

\section{Full Research Paper}

\section{Address:}

${ }^{1}$ Institut de Chimie Moléculaire et des Matériaux d'Orsay,UMR CNRS 8182, Université Paris-Sud, 15 rue Georges Clémenceau, 91405 Orsay Cedex, France, ${ }^{2}$ Laboratoire de Chimie de la Matière Condensée de Paris, Université Pierre et Marie Curie-Paris 6 and CNRS Collège de France, 11 place Berthelot 75231 Paris, France and ${ }^{3}$ Laboratoire de Chimie Physique, UMR CNRS 8000, Université Paris-Sud, 15 avenue Jen Perrin, 91405 Orsay Cedex, France

\section{Email:}

Anne Bleuzen* - anne.bleuzen@u-psud.fr

* Corresponding author

Keywords:

nanopatterning; nanoperforated oxide monolayer; Prussian blue analogues
Beilstein J. Nanotechnol. 2014, 5, 1933-1943.

doi:10.3762/bjnano.5.204

Received: 30 June 2014

Accepted: 08 October 2014

Published: 31 October 2014

This article is part of the Thematic Series "Molecular materials - towards quantum properties".

Guest Editor: M. Ruben

(c) 2014 Trannoy et al; licensee Beilstein-Institut.

License and terms: see end of document.

\begin{abstract} process.

Introduction

The development of methods to place nanoparticles into spatially well-defined, ordered arrays is one challenging aspect of nanotechnology. This is usually achieved by using top-down approaches, implementing optical and electron beam lithography. Here, we explore the possibilities of elaborating nanopatterned surfaces by a pure bottom-up approach.
\end{abstract}

Ordered nanoperforated $\mathrm{TiO}_{2}$ monolayers fabricated through sol-gel chemistry were used to grow isolated particles of Prussian blue analogues (PBA). The elaboration of the $\mathrm{TiO}_{2} / \mathrm{CoFe} \mathrm{PBA}$ nanocomposites involves five steps. The samples were characterized by scanning electron microscopy (SEM), atomic force microscopy (AFM), infrared spectroscopy and X-ray photoelectron spectroscopy (XPS) all along the synthesis process. Selected physico-chemical parameters have been varied in order to determine the key steps of the synthesis process and to optimize it. This study is an important step towards the full control of the fabrication

The nanopatterned surfaces are mainly built from molecular precursors in solution through a succession of chemical steps.
The advantages of this approach are very low fabrication costs, and easy adaptability of the fabrication process to the industrial scale. Our synthesis process is based on two main chemistries. The positioning of the functional objects and their isolation from each other is realized thanks to the exceptional processing flexibility inherent to sol-gel chemistry combined with organic templating agents. Coordination chemistry allowing for the controlled assembly of a large variety of transition metal building units is preferred to build the functional compound. 
Prussian blue analogs (PBAs) are interesting for the design of bistable compounds for two reasons. Firstly, some of them are molecular magnets with an ordering magnetic temperature that can exceed room temperature $[1,2]$. Secondly, some PBAs exhibit a photomagnetic effect $[3,4]$. Thus, in some CoFe Prussian blue analogs, an irradiation in the visible range transforms a diamagnetic state into a ferrimagnetic state with a long life time. This photomagnetic effect is interesting for high-density storage since the property of bistability is intrinsically molecular and therefore persists up to molecular scale [5-8]. These coordination polymers are obtained by a reaction between hexacyanometalates and hydrated cations of the transition metal series in aqueous solution. The resulting solid exhibits the wellknown face centered cubic structure of Prussian blue [9].

The sol-gel process is a method for producing metal oxides from small molecules via inorganic polymerization reactions in solution. The sol-gel transition allows one to obtain the oxide in any desired shape including films, fibers, monolithes [10]. Furthermore, the addition of self-assembling liquid crystalline templates to the sol can lead to the ordered nanostructuration of the oxide matrix [11]. Thus, nanoperforated thin layers, exhibiting hexagonal arrays of nanoperforations aligned perpendicular to the surface of the film surface have been developed $[12,13]$. These nanoperforated films are particularly appealing to organize isolated bistable dots on a solid surface [14,15].

The elaboration of the oxide/Prussian blue analogue nanocomposite involves five main steps, which have been described elsewhere for the fabrication of nanometer-scale patterns of photoswitchable PBA [15]. The substrate is first covered with a gold layer through sputtering, which will allow for the chemical differentiation of the surfaces and therefore their selective functionalization in the following. The second step is the deposition through dip-coating of an ethanolic solution of titanium molecular species containing block copolymers to obtain an ordered nanostructured organic-inorganic hybrid layer. The third step is a thermal treatment, which induces the decomposition of the organic part and the crystallization of the titanium dioxide leading to the nanoperforated layer. The fourth step is the selective functionalization of the surfaces to localize the PBA growth within the perforations while avoiding its formation outside. The last step is the PBA growth by a layer-by-layer directed assembly approach inspired from methods already implemented for the synthesis of PBA thin films [16-18].

Here, we study the impact of each step on the structure of the nanocomposite. We show that the first gold layer can undergo some changes in the course of the fabrication process and has to be optimized in order to obtain well-ordered nanoperforated oxide layers. We also show that the density of filled perfora- tions strongly depends on physico-chemical parameters used for the PBA growth step, which turns out to be the trickiest step of the elaboration process.

\section{Experimental Synthesis of the $\mathrm{TiO}_{2} / \mathrm{PBA}$ nanocomposite}

The five steps involved in the fabrication of the $\mathrm{PBA} / \mathrm{TiO}_{2}$ nanocomposites are the following [15]: In a first step, the silicon substrate is covered by a gold layer by sputtering under vacuum in a sputter coater (Quorum, Q150T ES) for use in scanning electron microscopy. This gold layer will allow for the chemical differentiation of the surfaces in the following. Layers having thicknesses of $10 \mathrm{~nm}, 20 \mathrm{~nm}$ and $50 \mathrm{~nm}$ were deposited under an electric current of $30 \mathrm{~mA}$ during calibrated times $(30 \mathrm{~s}$, $60 \mathrm{~s}$ and $150 \mathrm{~s}$ ). The three samples resulting from this first step and corresponding to the different thicknesses are called Au10, Au20 and Au50 in the following (see below in Table 1).

The second step is the deposition by dip-coating of an ethanolic solution of titanium molecular species containing block copolymers micelles that after evaporation are self-assembled to obtain an ordered nanostructured organic-inorganic hybrid layer. The solution for dip-coating was prepared by dissolving $37.5 \mathrm{mg}$ of polybutadiene-block-poly(ethylene oxide) $\left(M_{\mathrm{w}}(\mathrm{PB})=22000 \mathrm{~g} \cdot \mathrm{mol}^{-1}, M_{\mathrm{w}}(\mathrm{PEO})=15500 \mathrm{~g} \cdot \mathrm{mol}^{-1}\right)$ in $9.85 \mathrm{~g}$ of EtOH and $0.5 \mathrm{~g}$ of $\mathrm{H}_{2} \mathrm{O}$ at $70{ }^{\circ} \mathrm{C}$ for $2 \mathrm{~h}$. It was added then $0.27 \mathrm{~g}$ of an ethanolic solution of $\mathrm{TiCl}_{4}$ (molar ratio 1:5) $[12,19]$. The deposition of the film was performed under controlled conditions of temperature of the chamber $\left(80^{\circ} \mathrm{C}\right)$, of ascent speed $(2 \mathrm{~mm} / \mathrm{s})$ and of humidity rate $(<2 \%)$.

The third step is a thermal treatment under an IR-lamp at $450{ }^{\circ} \mathrm{C}$ over $5 \mathrm{~min}$, which results in the decomposition of the organic part and the crystallization of the titanium dioxide leading to the nanoperforated layer (ca. $15 \mathrm{~nm}$ ) with homogeneous and ordered holes (50 $\mathrm{nm}$ in diameter) giving access to the gold layer underneath (Scheme 1) [15]. The three samples resulting from this third step and corresponding to the three different thicknesses of the gold layer are called Au10NC, Au20NC and Au50NC in the following (see below in Table 1).

The fourth step is the selective functionalization of the surfaces. In order to prevent the formation of PBA outside the nanoperforations, the $\mathrm{TiO}_{2}$ surface was passivated by grafting with hydrophobic groups. The sample was placed in a solution of phenylphosphonic acid $\left(3 \cdot 10^{-3} \mathrm{M}\right)$ in an ethanol/water mixture $\left(3: 1 \mathrm{EtOH} / \mathrm{H}_{2} \mathrm{O}\right)$ for $12 \mathrm{~h}$. The film was rinsed with $\mathrm{EtOH}$ and acetone and allowed to dry at $120{ }^{\circ} \mathrm{C}$ for $2 \mathrm{~h}$. Then, an anchoring layer for PBA was grafted onto the gold bottom of the nanoperforations by dipping the substrate in an ethanolic 


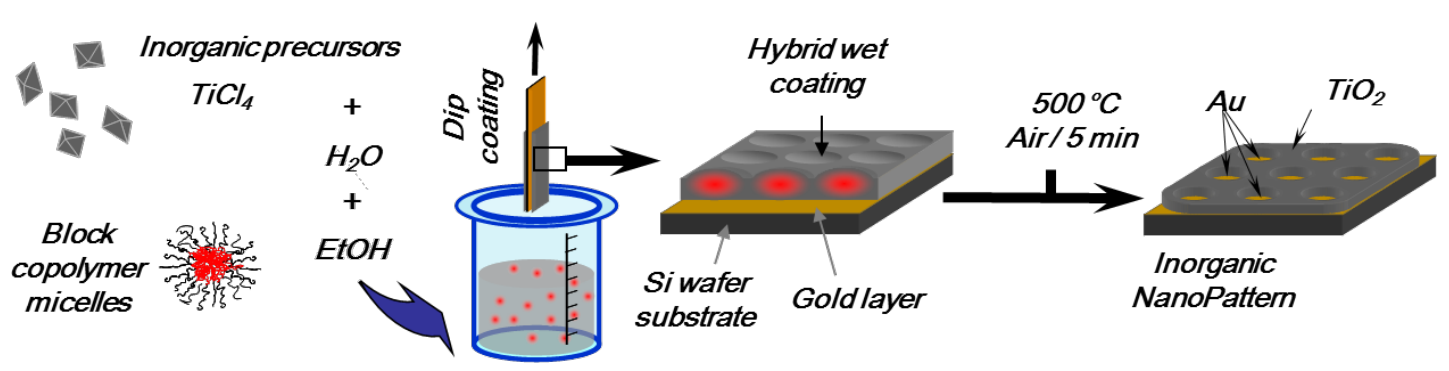

Scheme 1: Fabrication of the nanoperforated $\mathrm{TiO}_{2}$ layer (steps 2 and 3).

solution of mercaptohexanoic acid $\left(3 \cdot 10^{-3} \mathrm{M}\right)$, 4-mercaptopyridine $\left(3 \cdot 10^{-3} \mathrm{M}\right)$ or 4-aminothiophenol $\left(3 \cdot 10^{-3} \mathrm{M}\right)$ for $12 \mathrm{~h}$. Mercaptohexanoic acid, 4-mercaptopyridine or 4-aminothiophenol are abbreviated as MHA, 4-MPy and 4-ATP, respectively, in the following. The film was rinsed with $\mathrm{EtOH}$ and water. Scheme 2 shows the successive functionalization steps of the film in the case of the MHA anchorage [20,21].

The last step is the PBA growth through a layer-by-layer approach consisting of successive immersions of the functionalized substrate in PBA precursor solutions. The substrate was first immersed in a hexaaquacobalt(II) solution for $12 \mathrm{~h}$. Then, it was successively immersed for $2 \mathrm{~min}$ in a $3 \cdot 10^{-3} \mathrm{M}\left[\mathrm{Fe}(\mathrm{CN})_{6}\right]^{3-}$ aqueous solution and in a $10^{-1} \mathrm{M}$ $\left[\mathrm{Co}\left(\mathrm{H}_{2} \mathrm{O}\right)_{6}\right]^{2+}$ aqueous solution. The substrate was carefully rinsed with water after each immersion. The sample was dipped 15 times in both solutions (Scheme 3) [15].
The same protocol was carried out while replacing the water solvent with i) butanol for the $\mathrm{Co}^{2+}$ solution and ethanol/ water $\left(1: 1 \mathrm{EtOH} / \mathrm{H}_{2} \mathrm{O}\right)$ for the $\left[\mathrm{Fe}(\mathrm{CN})_{6}\right]^{3-}$ solution and ii) ethanol/water $\left(1: 1 \mathrm{EtOH} / \mathrm{H}_{2} \mathrm{O}\right)$ for the $\mathrm{Co}^{2+}$ solution and for the $\left[\mathrm{Fe}(\mathrm{CN})_{6}\right]^{3-}$ solution. The name and the conditions used for the preparation of the samples resulting from this fifth step are gathered in Table 1 (NC01-NC05).

\section{Materials characterization}

SEM images were obtained by using a field emission gun scanning electron microscope (FEG-SEM Zeiss Sigma HD microscope) equipped with an in-lens detector working at $1 \mathrm{kV}$ and at a short working distance (WD) equal to $3.3 \mathrm{~mm}$ for the $\mathrm{TiO}_{2}$ thin film images and equipped with a secondary electron detector (SE) working at $1 \mathrm{kV}$ and at a short working distance (WD) equal to $3.8 \mathrm{~mm}$ for the $\mathrm{TiO}_{2} / \mathrm{PBA}$ nanocomposite images. Tapping mode topography and phase imaging was

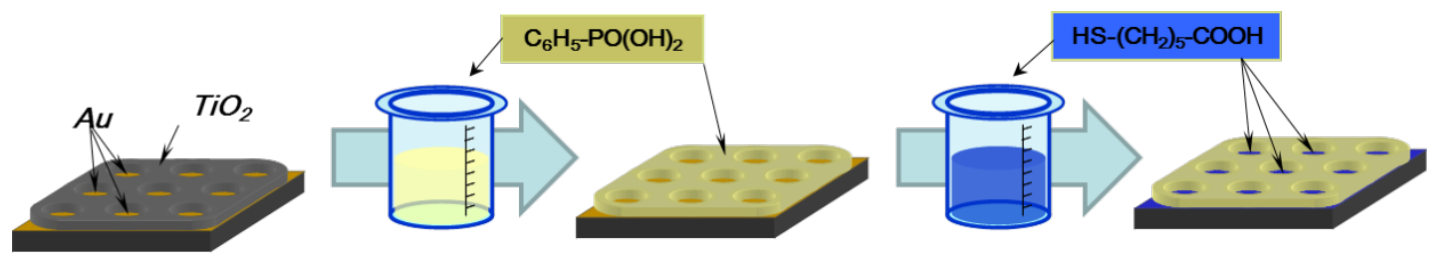

Scheme 2: Selective functionalization of the $\mathrm{TiO}_{2}$ and gold surfaces (step 4).

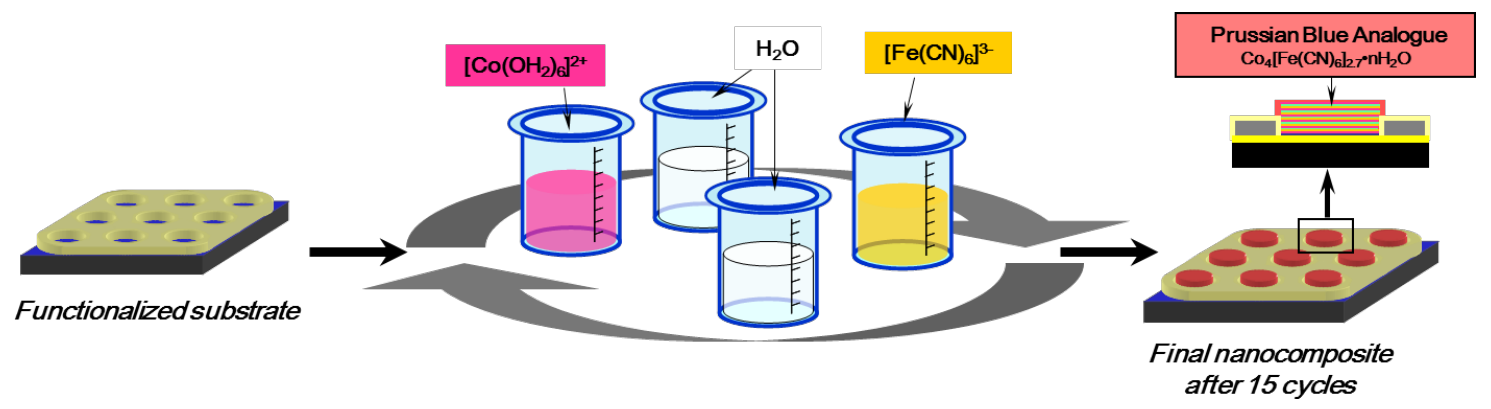

Scheme 3: Layer-by-layer PBA growth (step 5). 


\begin{tabular}{|c|c|c|c|c|c|}
\hline \multirow{2}{*}{ name of the sample } & \multirow{2}{*}{$\begin{array}{l}\text { thickness of the } \\
\text { gold layer/nm }\end{array}$} & \multirow{2}{*}{$\mathrm{TiO}_{2}$ deposition } & \multirow{2}{*}{$\begin{array}{l}\text { gold } \\
\text { functionalization }\end{array}$} & \multicolumn{2}{|c|}{$\begin{array}{c}\text { solvent or mixture of solvents for the PBA } \\
\text { precursor solution }\end{array}$} \\
\hline & & & & $\mathrm{Co}^{2+}$ & {$\left[\mathrm{Fe}(\mathrm{CN})_{6}\right]^{3-}$} \\
\hline Au10 & 10 & - & - & - & - \\
\hline Au20 & 20 & - & - & - & - \\
\hline Au50 & 50 & - & - & - & - \\
\hline Au10NC & 10 & $x$ & - & - & - \\
\hline Au20NC & 20 & $x$ & - & - & - \\
\hline Au50NC & 50 & $x$ & - & - & - \\
\hline NC01 & 20 & $x$ & MHA & $\mathrm{H}_{2} \mathrm{O}$ & $\mathrm{H}_{2} \mathrm{O}$ \\
\hline NC02 & 20 & $x$ & 4-ATP & $\mathrm{H}_{2} \mathrm{O}$ & $\mathrm{H}_{2} \mathrm{O}$ \\
\hline $\mathrm{NCO3}$ & 20 & $x$ & 4-MPy & $\mathrm{H}_{2} \mathrm{O}$ & $\mathrm{H}_{2} \mathrm{O}$ \\
\hline NC04 & 20 & $x$ & MHA & $\mathrm{BuOH}$ & $\mathrm{EtOH} / \mathrm{H}_{2} \mathrm{O}=1: 1$ \\
\hline NC05 & 20 & $x$ & MHA & $\mathrm{EtOH} / \mathrm{H}_{2} \mathrm{O}=1: 1$ & $\mathrm{EtOH} / \mathrm{H}_{2} \mathrm{O}=1: 1$ \\
\hline
\end{tabular}

accomplished by using an Innova AFM (Bruker) with NanoDrive v8.02 software. Tapping mode images were acquired by using silicon tips from Nanosensors (PPP NCSTR) with a resonance frequency ranging between 76 and $263 \mathrm{kHz}$. Images were processed by using WsXM software. Fourier transform-infrared (FTIR) spectra were collected in the attenuated total reflection (ATR) mode by using a Vertex 70 spectrometer with a germanium crystal. XPS spectra were collected on a SPECS (Phoibos MCD 150) X-ray photoelectron spectrometer, by using $\mathrm{Mg} \mathrm{K} \alpha(h v=1253.6 \mathrm{eV}) \mathrm{X}$-ray source having a $150 \mathrm{~W}(12 \mathrm{~mA}, 12.5 \mathrm{kV})$ electron beam power and a $7 \times 20 \mathrm{~mm}$ spot size. The emissions of photoelectrons from the sample were analyzed at a takeoff angle of $90^{\circ}$ under ultra-high vacuum conditions $\left(1 \cdot 10^{-8} \mathrm{~Pa}\right)$. High resolution spectra were collected at a pass energy of $10 \mathrm{eV}$ for $\mathrm{S} 2 \mathrm{p}$ core XPS levels. No charge compensation was applied during acquisition.

\section{Results and Discussion The gold layer}

The silicon wafer and the samples Au10, Au20 and Au50 were studied by AFM. Representative AFM images are shown in Figure 1. After gold deposition, whatever the deposition time, the silicon substrate is completely and homogeneously covered by gold nanoparticles (as expected for sputtering deposition).
But, the size of the particles depends on the deposition time. The gold layers obtained with $30 \mathrm{~s}, 60 \mathrm{~s}$ and $150 \mathrm{~s}$ deposition time are composed of gold nanoparticles of $10 \mathrm{~nm}, 15 \mathrm{~nm}$ and $40 \mathrm{~nm}$ in diameter, respectively. The roughness is $0.27 \mathrm{~nm}$ for the silicon substrate, $0.44 \mathrm{~nm}$ for the $10 \mathrm{~nm}$ thick gold layer, $0.48 \mathrm{~nm}$ for the $20 \mathrm{~nm}$ thick gold layer and $1.01 \mathrm{~nm}$ for the $50 \mathrm{~nm}$ thick one. After the gold deposition, the surfaces exhibit a small roughness and are therefore of good quality for the nanoperforated oxide layer deposition.

\section{The nanoperforated $\mathrm{TiO}_{2}$ monolayer}

The nanoperforated $\mathrm{TiO}_{2}$ monolayer deposited on the silicon wafer covered by a $10 \mathrm{~nm}$ thick gold layer (sample Au10) was studied by AFM and SEM. Representative AFM and SEM images are shown in Figure 2a and Figure 2b. Two different kinds of zones can be observed on the AFM and SEM pictures. Some lighter islands appear on the darker background. The fraction of the light areas can be estimated to be around $40 \%$. The dark spots correspond to nanoperforations aligned perpendicularly to the surface. Their depth has been estimated to be $15 \mathrm{~nm}$ and their diameter to be $50 \mathrm{~nm}$ (Figure S1 in Supporting Information File 1). The distance between two adjacent nanoperforations is $80 \mathrm{~nm}$. Whatever the area, light or dark, the 2D-hexagonal organization of the perforations is visible. This indicates
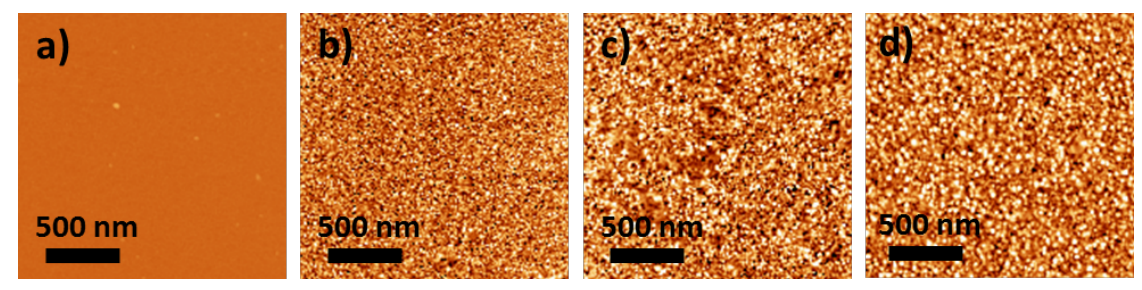

Figure 1: AFM images of a) the Si substrate b) Au10, c) Au20 and d) Au50. 
that the nanoperforated oxide film covers the whole surface. The two kinds of zones have been assigned to areas with and without gold between the silicon substrate and the perforated oxide layer. Figure $2 \mathrm{c}$ and Figure $2 \mathrm{~d}$ show the depth distribution histogram in the dark and light areas of the AFM image. This AFM study indicates that the bright zones have higher relief (up to $80 \mathrm{~nm}$ above the silicon wafer) with a wide height distribution. In contrast, the depth distribution histogram in dark areas shows a narrow distribution centered around $15 \mathrm{~nm}$ corresponding to the thickness of the $\mathrm{TiO}_{2}$ nanoperforated layer. This suggests a dewetting of the gold layer from the silicon surface to form gold droplets between the silicon wafer and the nanoperforated oxide layer corresponding to the light areas. The bottom of the nanoperforations in the dark areas would therefore be made of silicon rather than of gold. This hypothesis has been confirmed by energy dispersive X-ray analysis (EDX) performed in a bright and in a dark area. The results clearly show the presence of gold in the bright area, whereas this element is absent in the dark area (Figure S2 in Supporting Information File 1).
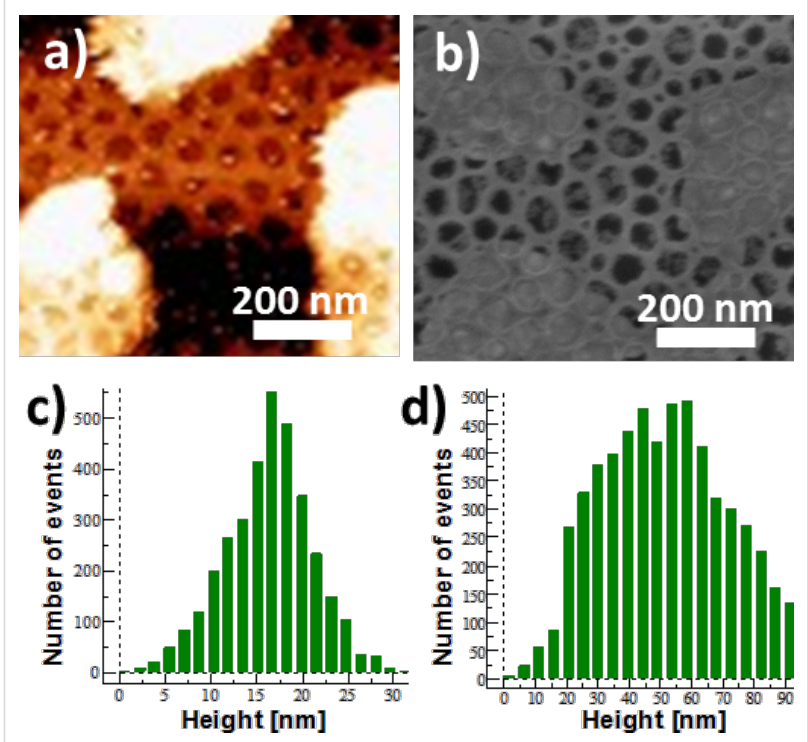

Figure 2: a) AFM and b) SEM images of the sample Au10NC. Depth distribution histogram in the $\mathrm{c}$ ) dark and d) light areas.

Nanoperforated $\mathrm{TiO}_{2}$ monolayers deposited on $20 \mathrm{~nm}$ and $50 \mathrm{~nm}$ thick gold layers (samples Au20NC and Au50NC) were also studied by AFM and SEM. Representative SEM images of Au20NC and Au50NC at a low magnification are shown in Figure 3, and AFM and SEM images with higher magnification are shown in Figure 4.

The SEM images of Au20NC and Au50NC show few dark islands of around $1 \mu \mathrm{m}$, standing out from the light background.

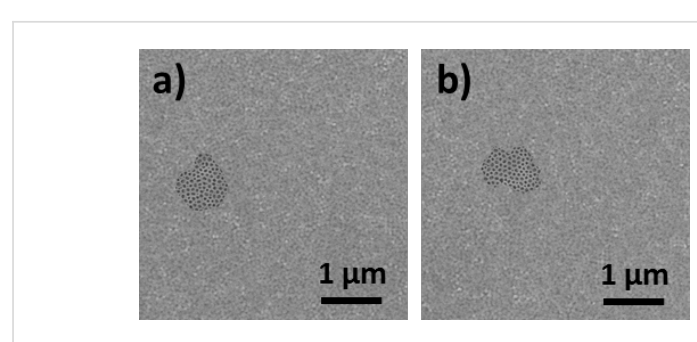

Figure 3: SEM micrographs of a) Au20NC and b) Au50NC.
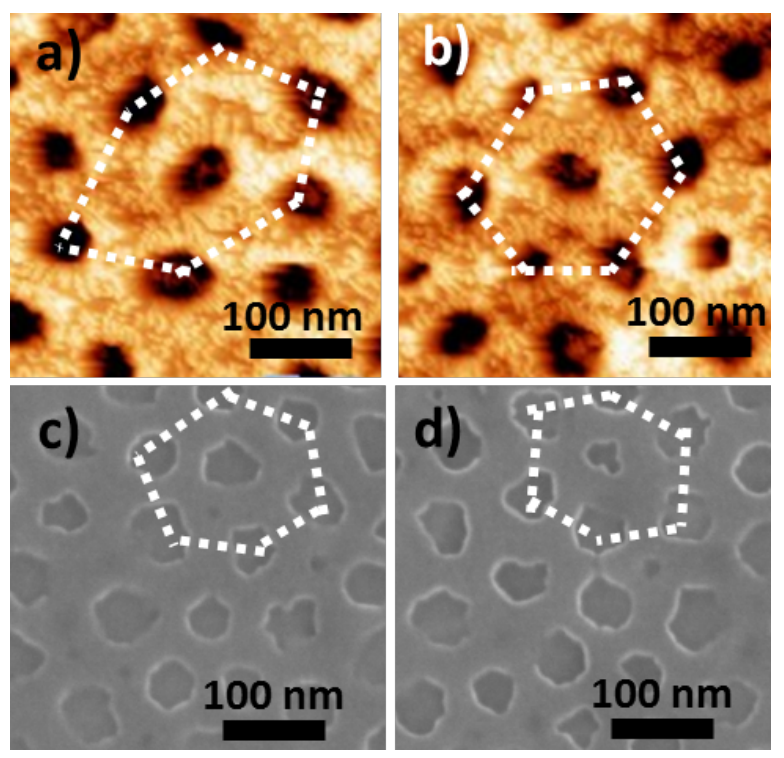

Figure 4: AFM images of a) Au20NC, b) Au50NC and SEM micrographs of c) Au20NC and d) Au50NC.

As for the sample Au10NC, the 2D organization of the nanoperforations is visible over the whole surface. The minority of dark areas (less than $6 \%$ of the whole surface) are assigned to zones where a dewetting of the gold layer from the silicon substrate occurred. In contrast to sample Au10NC, the gold layer still covers a great majority of the surface after the formation of the oxide nanoperforated layer.

Figure 4, corresponding to a magnification of the majority of light areas, shows that the AFM and SEM images of the films obtained with the $20 \mathrm{~nm}$ and the $50 \mathrm{~nm}$ gold layers are comparable. They show dark spots corresponding to nanoperforations of same depth and of same diameter as those obtained with the $10 \mathrm{~nm}$ thick gold layer and exhibiting a 2D-hexagonal organization (shown by the dashed lines in Figure 4). Nevertheless, the degree of hexagonal order is lower for these films deposited on gold layers than for films directly deposited on the silicon substrate [19,22-24]. This loss of order is probably due to matter displacement during the thermal treatment, leading to an accumulation of gold in some regions of the sample and to a lack of 
gold in others. As a consequence, the $\mathrm{TiO}_{2}$ nanoperforated layer forms on an undulating gold surface, which results in a certain lowering of the degree of long-range order.

Whatever the sample, the AFM and SEM studies also revealed the presence of some perforations, the bottom of which seems not to be completely cleared of $\mathrm{TiO}_{2}$. This effect is more visible in areas without gold. A SEM image corresponding to such areas of sample Au20NC is shown in Figure 5. A light grey pellicle, indicating the presence of $\mathrm{TiO}_{2}$, partially covers the bottom of some perforations.

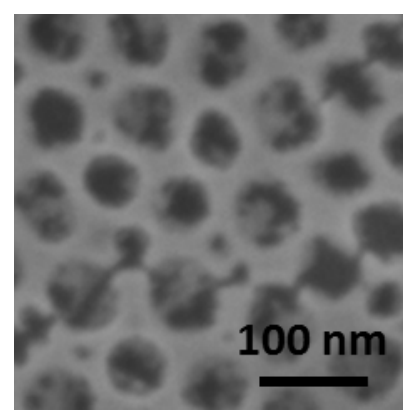

Figure 5: SEM image corresponding to a dark area of the sample Au20NC.

The non-homogeneous and non-planar surface exhibiting a different chemical nature of the bottom of the nanoperforations of the films deposited on a $10 \mathrm{~nm}$ thick gold layer, such as sample Au10NC, can be assigned to a dewetting of the gold layer from the silicon during the thermal treatment at $450{ }^{\circ} \mathrm{C}$. This inhomogeneity of the surface led us to exclude samples with such gold layers for the study. The films synthesized with the $20 \mathrm{~nm}$ thick gold layer, such as sample Au20C, were used in the following without further optimization. Nevertheless, this study shows an unexpected behavior of the gold layer, which has to be optimized in the future.

\section{Functionalization of the $\mathrm{Au}$ and $\mathrm{TiO}_{2}$ surfaces}

To localize the growth of PBA into the nanoperforations, a selective functionalization of the $\mathrm{Au}$ and $\mathrm{TiO}_{2}$ surfaces has been implemented. The oxide surface is rendered hydrophobic in order to prevent the adsorption of PBA precursors. The phosphonate function allows for the selective grafting of the phenyl group on $\mathrm{TiO}_{2}[20,21]$. Then, MHA, 4-MPy or 4-ATP are used as coupling agents for anchoring a first layer of $\mathrm{Co}^{2+}$ ions at the bottom of the nanoperforations.

To evaluate the efficiency of the $\mathrm{TiO}_{2}$ functionalization, this step was omitted while the functionalization with MHA and the growth of CoFe PBA in aqueous solution were performed. A representative SEM image of this sample is shown in Figure 6. The whole surface seems bumpy as if a crust constituted by very small PBA particles covered it and under which the nanoperforations are hardly visible. Without hydrophobization of $\mathrm{TiO}_{2}, \mathrm{PBA}$ precursors interact with the accessible oxide surface leading to the formation of PBA particles everywhere.

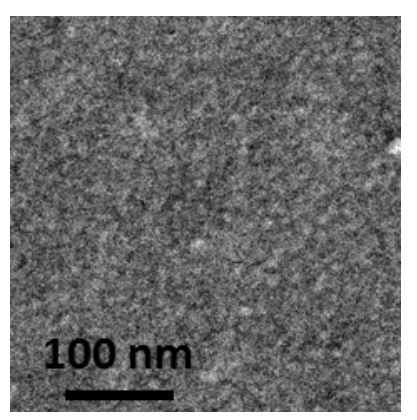

Figure 6: SEM image corresponding to CoFe PBA grown on the nanoperforated films without prior functionalization of $\mathrm{TiO}_{2}$.

In order to verify the effectiveness of the gold functionalization through the MHA anchoring function at the bottom of the perforations, the presence of sulfur atoms at the surface of the sample was monitored by X-ray photoelectron spectroscopy (XPS) throughout the functionalization step. XPS was carried out right after removing the sample from the MHA solution and after rinsing with EtOH (Figure 7). Before rinsing (Figure 7a), the spectrum exhibit two doublets that can be assigned to a free thiol function and a thiolate species bound to the gold surface $[25,26]$. After rinsing, the band characteristic of the free function has disappeared (Figure $7 \mathrm{~b}$ ). But, the band corresponding to bound thiolate species still remains. The grafting of the gold surface with MHA therefore was successful.

The effect of the functionalized gold layer at the bottom of the perforations on the growth of PBA is nicely illustrated by a SEM image of the film exhibiting areas with and without gold after PBA growth. PBA particles are concentrated in the areas with gold at the bottom of the nanoperforations, whereas the areas without gold are almost completely free of PBA particles (Figure S3 in Supporting Information File 1).

\section{$\mathrm{TiO}_{2} / \mathrm{PBA}$ nanocomposites Microscopy study}

The $\mathrm{TiO}_{2} / \mathrm{CoFe}$ PBA nanocomposite NC01 synthesized by using MHA as anchor and water as the solvent was studied by AFM and SEM. Representative AFM and SEM images of the sample NC01 are shown in Figure 8a and Figure 8c. The height profile along the green dashed line passing through one hole and three particles on the AFM image is shown in Figure 8b. 

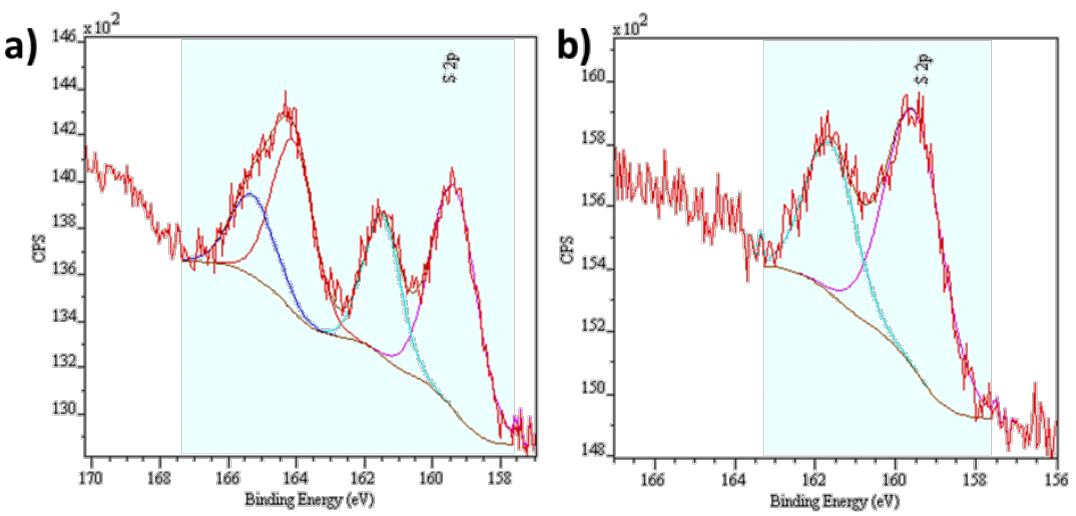

Figure 7: XPS spectra of a film immersed in MHA solution a) before and b) after rinsing with EtOH.

The AFM and SEM images show the 2D-hexagonal arrangement of the nanoperforations and some light objects assigned to PBA particles localized on some of the nanoperforations (Figure 8a and Figure 8c). The shape of the particles is spherical or half-spherical. On the TEM image it is difficult to see if the particles are located in the pores or on the $\mathrm{TiO}_{2}$ grid. On the contrary, in the AFM image, the particles clearly seem to be located in the nanoperforations. Furthermore, the AFM height profile (Figure $8 \mathrm{~b}$ ) shows three maxima and one minimum corresponding to three particles and one perforation. The distance between these maxima and minimum fairly corresponds to the distance between adjacent nanoperforations of the $\mathrm{TiO}_{2}$ film before PBA growth (see above), which supports the location of the particles on the nanoperforations. Nevertheless, one cannot conclude whether or not the particles are anchored to the bottom of the perforations.

Each particle seems to be located on one perforation, but not all of the nanoperforations are filled. The average rate of perforations containing one PBA particle is around $15 \%$. The localization of the PBA particles in the perforations indicates that the hydrophobic groups have successfully passivated the oxide surface. The partial loading of the perforations by PBA particles can be due to several reasons listed below:

- the presence of $\mathrm{TiO}_{2}$ at the bottom of the perforations, which have been rendered hydrophobic when the substrate has been immersed in phenylphosphonic acid, which prevents i) the grafting of the anchoring function for PBA growth and ii) the adsorption of any of the PBA precursors or PBA particles;

- a low yield of the complexation reaction of the $\mathrm{Co}^{2+}$ ions by the anchoring functions grafted onto the bottom of the nanoperforations;

- the occurrence of dissolution-recrystallization phenomena during the PBA growth step: during the successive immersions of the functionalized film, the particles or a few of the particles formed during the first cycles can dissolve and the released precursors reform new particles.

The size of the PBA particles ranges from 20 to $100 \mathrm{~nm}$. The size of the smallest particles is of the order of magnitude expected for PBA particles formed by a layer-by-layer ap-
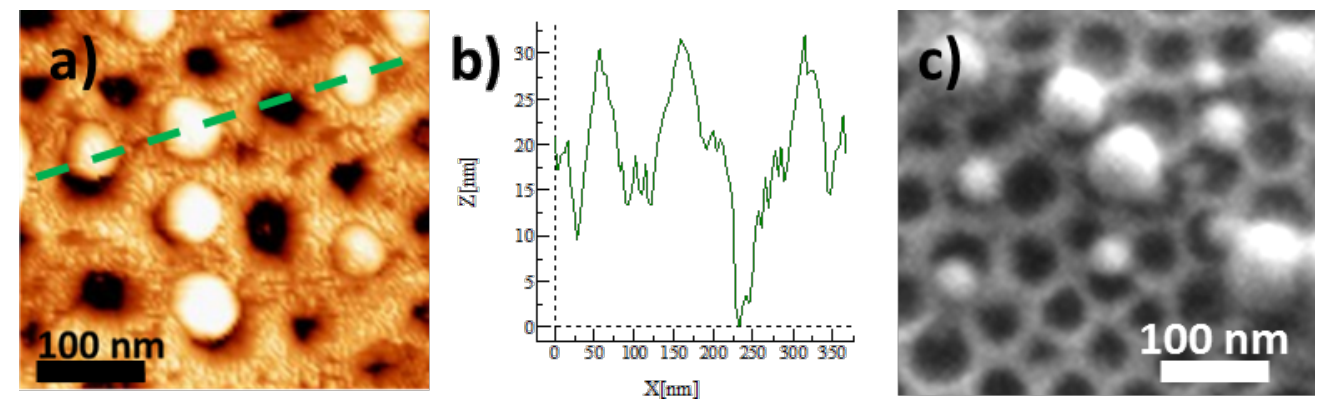

Figure 8: a) AFM image, b) height profile along the green dotted line on the AFM image and c) SEM image of NC01. 
proach since 15 units of $-\mathrm{Fe}-\mathrm{CN}-\mathrm{Co}-$ (corresponding to 15 cycles) corresponds to approximately $8 \mathrm{~nm}$. Therefore, a growth from Co ions anchored to the bottom of the perforations could result in half-spherical particles of $16 \mathrm{~nm}$ in diameter. The formation of particles of bigger size can be explained by the occurrence of dissolution-recrystallization phenomena.

Effect of the chemical nature of the anchoring function for PBA: The $\mathrm{TiO}_{2} / \mathrm{CoFe}$ PBA nanocomposites NC02 synthesized by using 4-MPy (Figure 9a and Figure 9c) and NC03 synthesized by using 4-ATP (Figure 9b and Figure 9d) as anchoring functions while keeping water as the solvent were studied by AFM and SEM. Representative AFM and SEM images are shown Figure 9.

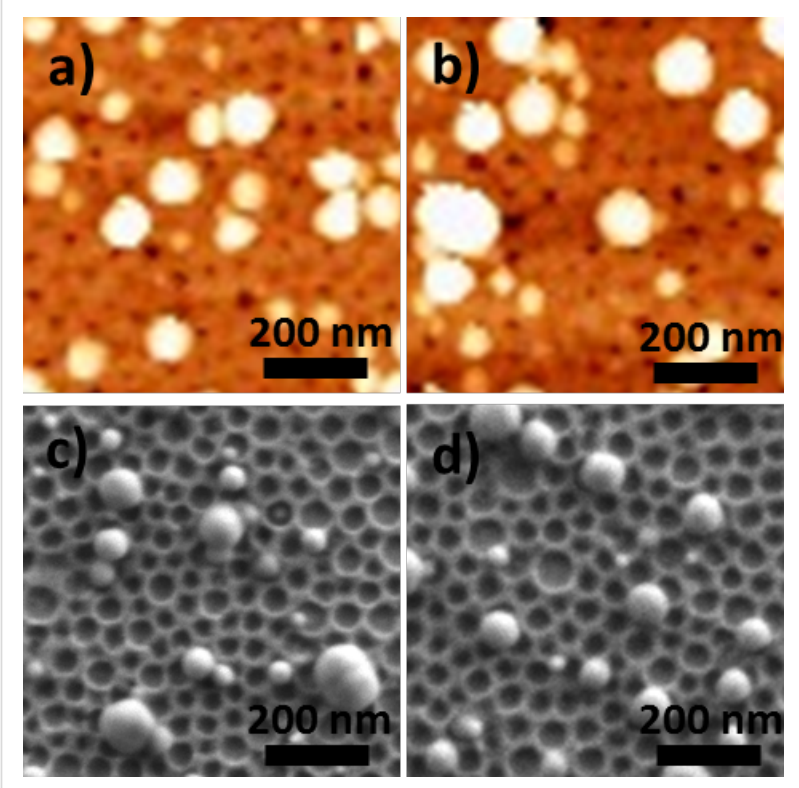

Figure 9: AFM images of a) $\mathrm{NCO2,} \mathrm{b)} \mathrm{NC03}$ and SEM micrographs of c) $\mathrm{NCO2}$, d) $\mathrm{NCO}$.

The AFM and SEM images are very similar to those obtained with MHA. They show the same spherical or half-spherical particles localized on the nanoperforations. The size of these PBA particles ranging from 20 to $80 \mathrm{~nm}$ in diameter is comparable to that of the previous sample. As before, around $15 \%$ of the nanoperforations are filled with PBA particles. The chemical nature of the complexing agent for the transition metal ion seems to play little or no role in the growth process of the PBA particles.

Effect of the solvent or of the solvent mixture of the PBA precursors solutions: The $\mathrm{TiO}_{2} / \mathrm{CoFe} \mathrm{PBA}$ nanocomposites synthesized by using alcohol or a water/alcohol mixture for the PBA growth were studied by AFM and SEM. Figure 10a and
Figure 10c show representative AFM and SEM images of the $\mathrm{TiO}_{2} / \mathrm{CoFe}$ PBA nanocomposite $\mathrm{NCO4}$ synthesized by using a butanolic $\mathrm{Co}^{2+}$ solution and $\left[\mathrm{Fe}(\mathrm{CN})_{6}\right]^{3-}$ in a $1: 1 \mathrm{EtOH} / \mathrm{H}_{2} \mathrm{O}$ mixture as PBA precursors solutions. Figure $9 \mathrm{~b}$ and Figure $9 \mathrm{~d}$ show representative AFM and SEM images of the $\mathrm{TiO}_{2} / \mathrm{CoFe}$ PBA nanocomposite $\mathbf{N C 0 5}$ synthesized by using solutions of $\mathrm{Co}^{2+}$ in a $1: 1 \mathrm{EtOH} / \mathrm{H}_{2} \mathrm{O}$ mixture and $\left[\mathrm{Fe}(\mathrm{CN})_{6}\right]^{3-}$ in $1: 1$ EtOH/ $\mathrm{H}_{2} \mathrm{O}$ mixture as PBA precursors solutions. The AFM and SEM images are very different from those of the previous samples (NC01 to NC03). This difference shows the important role of the reaction medium for PBA growth. The images show a great number of faceted particles with a pyramidal shape or a cubic shape with one corner inserted in one perforation.
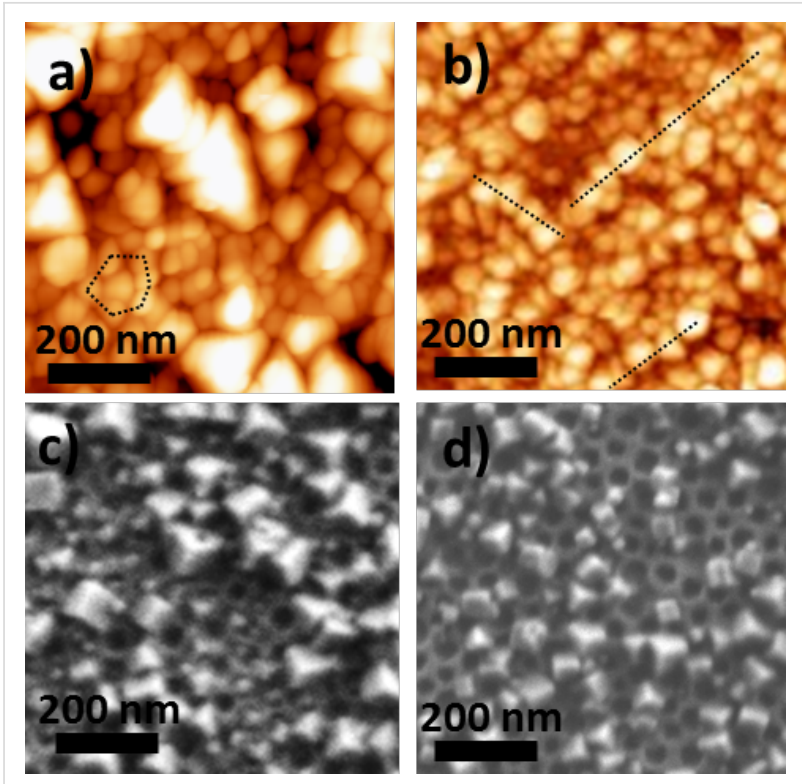

Figure 10: AFM images of a) NC04, b) NC05 and SEM micrographs of c) $\mathrm{NC04}$, d) $\mathrm{NC0}$.

Except some differences in the particles size range, which seems somewhat larger in the case of NC04 than in the case of $\mathrm{NC05}$, the AFM and SEM images of $\mathrm{NC04}$ and of $\mathrm{NC05}$ are very similar. The average density of filled perforations is very high for the two samples, which makes it difficult to see if the particles are localized in the perforations. However, some organization of the particles can be seen in the AFM images (dotted lines in Figure 10a and Figure 10b), which could result from the organization of the perforations. For instance, a hexagonal organization of some particles is visible and the distance between the aligned particles fairly corresponds to the distance between the centers of the perforations. NC04 and NC05 exhibit particles with a completely different shape compared to samples NC01 to NC03. Because the particles have the same chemical composition (see IR spectroscopic study below), these different shapes probably reflect different determining factors in the 
particles formation. Indeed, different shapes for particles of same chemical composition usually correspond to growth rates limited by different parameters. PBA particles crystallize in the $F m-3 m$ cubic face centered space group. They are often cubic due to different interface energies for the different crystallographic faces and therefore different growth rates leading to the formation of cubic particles. Nevertheless, under some specific conditions of concentrations, spherical particles can be obtained when the growth reaction rate is limited by the diffusion of the precursors. In the case of the films, the pyramidal or cubic shape is systematically obtained when the reaction medium is $\mathrm{BuOH}$ or the $1: 1$ mixture $\mathrm{EtOH} / \mathrm{H}_{2} \mathrm{O}$ whereas the half-spherical or spherical shape is obtained in aqueous solutions. PBA particles are less soluble in $\mathrm{BuOH}$ and in the $\mathrm{EtOH} / \mathrm{H}_{2} \mathrm{O}$ mixture than in $\mathrm{H}_{2} \mathrm{O}$ and therefore the dissolution-recrystallization rates are different. The diffusion rates of the precursors in the two reaction media are also different. These differences probably accounts for the different shape of the particles.

A pyramidal shape has been predicted by Tricard et al. [27,28] for a layer-by-layer growth process without additional dissolution-recrystallization phenomena. The study of the mechanisms involved in the PBA nanoparticles growth is still in progress and seems to be more complicated than the layer-bylayer process often evoked in the literature to describe the growth of PBA films [16-18].

\section{Infrared spectroscopic investigation}

Infrared spectroscopy, and especially the $v(\mathrm{C} \equiv \mathrm{N})$ vibration band located in the spectral range of $2100-2200 \mathrm{~cm}^{-1}$ is usually used to characterize PBA species. Indeed, the cyanide bridge is extremely sensitive to its environment, including the oxidation state and the spin state of the transition metal ions [29].

Because samples NC01 to NC03 on the one hand and samples $\mathrm{NC04}$ and NC05 on the other hand are very similar, the results are presented for samples NC01 and NC04. The spectra of NC01 and NC04 are shown in the range of 1900-2250 $\mathrm{cm}^{-1}$ in Figure 11. Both spectra display one narrow and intense band centered at $2106 \mathrm{~cm}^{-1}$. This band is attributed to the $\mathrm{CN}$ stretching vibration. The position of the band corresponds neither to a terminal $\mathrm{Fe}^{\mathrm{III}}-\mathrm{CN}$ group (expected around $2118 \mathrm{~cm}^{-1}$ ) [29] nor to a $\mathrm{Fe}^{\mathrm{II}}-\mathrm{CN}$ group (expected around $2044 \mathrm{~cm}^{-1}$ ) [29]. The narrowness of this band and its energy position are in line with the formation of a CoFe PBA. The band is located at the same energy (within the experimental resolution) in both spectra. This indicates the formation of PBA of the same chemical composition for all the samples. The position of the band corresponds to $\mathrm{CN}$ in $\mathrm{Fe}^{\mathrm{II}}-\mathrm{CN}-\mathrm{Co}^{\mathrm{II}}$ linkages of the $\mathrm{Co}^{\mathrm{II}} \mathrm{Fe}^{\mathrm{II}}$ PBA. Starting from $\mathrm{Co}^{\mathrm{II}}$ and $\left[\mathrm{Fe}^{\mathrm{III}}(\mathrm{CN})_{6}\right]^{3-}$ ions as PBA precursors, the energy position of the band indicates the reduction of $\left[\mathrm{Fe}^{\mathrm{III}}(\mathrm{CN})_{6}\right]^{3-}$ into $\left[\mathrm{Fe}^{\mathrm{II}}(\mathrm{CN})_{6}\right]^{4-}$ during the formation of PBA. Such a reduction reaction during the synthesis of PBA thin films has already been observed [30]. The strong difference in the intensity of the band from NC04 to NC01 reflects different amounts of PBA on the surface of the films. The intensity ratio of the bands of $\mathrm{NCO4}$ and $\mathrm{NCO1}$ is 15\% in agreement with the average density of filled perforations determined by microsopy: around 15\% for NC01 and very high, close to $100 \%$, for $\mathrm{NCO4}$.

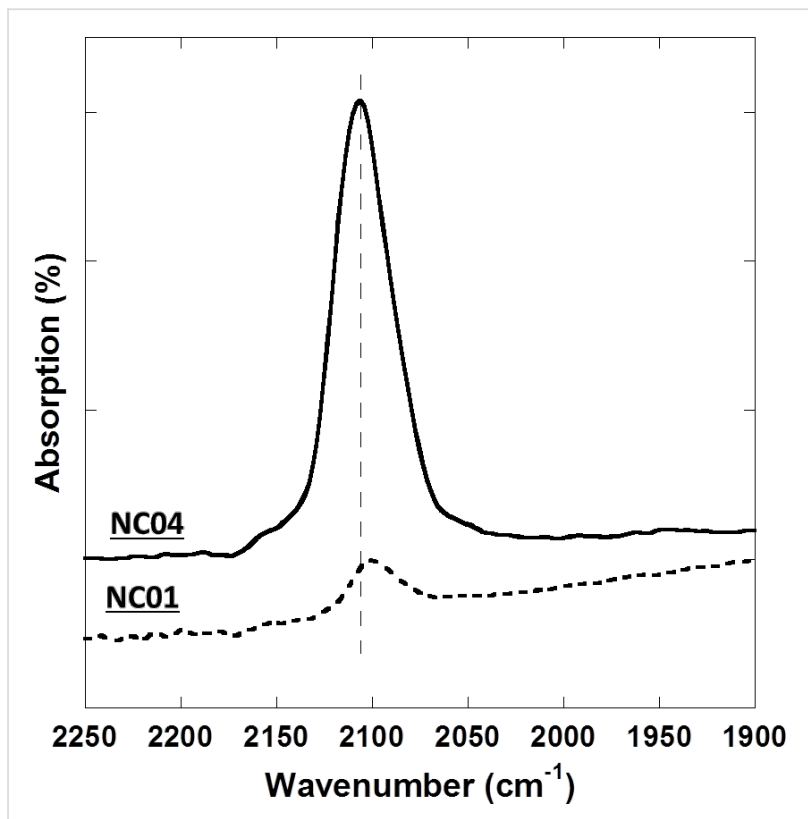

Figure 11: IR spectra of NC01 and NC04.

\section{Conclusion}

In conclusion, this first approach to study step-by-step the controlled growth of PBA particles within the perforations of ordered nanoperforated oxide layers allows for pointing out the steps the optimization of which would improve the final composite. Some steps are well-controlled or already optimized and some others are trickier and need to be optimized in order to get perfectly ordered nanoperforated layers with all the perforations filled with PBA particles.

After deposition, the small roughness of the gold layer is suitable for the subsequent deposition of the oxide layer. Nevertheless, the morphology of this layer undergoes important changes during the thermal treatment (step 3). The evolution is spectacular in the case of the $10 \mathrm{~nm}$ thick gold layer, but also exists for the layers with higher thicknesses. The unexpected thermal behavior of the gold layer shows that the first step clearly needs to be optimized to avoid any gold displacement modifying the planarity of the layer, which necessarily affects the ordered organization of the nanoperforations. 
The deposition (step 2) and the thermal treatment (step 3) of the ordered hybrid organic-inorganic layer have already been extensively studied $[12,19]$. The smaller the diameters of the perforations are, the higher is the degree of order. Nevertheless, a perfect accessibility of the gold bottom of all the perforations is mandatory in order to fill all of them with PBA particles. Work is in progress to check and to improve this point.

The selective functionalization of the surfaces is a necessary step to localize PBA growth within the nanoperforations. The hydrophobization of the accessible oxide layer efficiently avoids the formation of PBA outside the perforations. The chemical nature of the anchoring function for the PBA growth seems not to be a determining factor in the average density of filled perforations.

The growth of PBA is undoubtedly the trickiest step. The average density of filled perforations and the shape of the particles seem strongly linked to the solubility of the growing particles in the reaction media. Work is in progress in order to fully control this step.

\section{Supporting Information}

\section{Supporting Information File 1}

Additional experimental data.

[http://www.beilstein-journals.org/bjnano/content/ supplementary/2190-4286-5-204-S1.pdf]

\section{Acknowledgements}

This research was carried out with the support of C'Nano IdF, the University Paris-Sud and the University Paris 6. Virgile Trannoy thanks Region Ile-de-France C'Nano program for the Ph.D. financial support.

\section{References}

1. Entley, W. R.; Girolami, G. S. Science 1995, 268, 397-400. doi:10.1126/science.268.5209.397

2. Ferlay, S.; Mallah, T.; Ouahes, R.; Veillet, P.; Verdaguer, M. Nature 1995, 378, 701-703. doi:10.1038/378701a0

3. Sato, O.; Iyoda, T.; Fujishima, A.; Hashimoto, K. Science 1996, 272, 704-705. doi:10.1126/science.272.5262.704

4. Bleuzen, A.; Lomenech, C.; Escax, V.; Villain, F.; Varret, F.; Cartier dit Moulin, C.; Verdaguer, M. J. Am. Chem. Soc. 2000, 122, 6648-6652. doi:10.1021/ja000348u

5. Li, D.; Clérac, R.; Roubeau, O.; Harté, E.; Mathonière, C.; Le Bris, R.; Holmes, S. M. J. Am. Chem. Soc. 2008, 130, 252-258. doi:10.1021/ja0757632

6. Mercurol, J.; Li, Y.; Pardo, E.; Risset, O.; Seuleiman, M.; Rousselière, H.; Lescouëzec, R.; Julve, M. Chem. Commun. 2010, 46, 8995-8997. doi:10.1039/c0cc02024a
7. Hoshino, N.; lijima, F.; Newton, G. N.; Yoshida, N.; Shiga, T.; Nojiri, H.; Nakao, A.; Kumai, R.; Murakami, Y.; Oshio, H. Nat. Chem. 2012, 4, 921-926. doi:10.1038/nchem.1455

8. Cafun, J.-D.; Cartier dit Moulin, C.; Fornasieri, G.; Arrio, M.-A.; Briois, V.; Bleuzen, A. New J. Chem. 2011, 35, 2074-2080. doi:10.1039/c1nj20180h

9. Ludi, A.; Güdel, H. Structural chemistry of polynuclear transition metal cyanides. Inorganic Chemistry; Structure and Bonding, Vol. 14; Springer: Berlin, Germany, 1973; pp 1-21. doi:10.1007/BFb0016869

10. Brinker, C. J.; Scherer, G. W., Eds. Sol-Gel Science: The Physics and Chemistry of Sol-Gel Processing; Gulf Professional Publishing, 1990.

11. Kresge, C. T.; Leonowicz, M. E.; Roth, W. J.; Vartuli, J. C.; Beck, J. S. Nature 1992, 359, 710-712. doi:10.1038/359710a0

12. Fisher, A.; Kuemmel, M.; Järn, M.; Linden, M.; Boissière, C.; Nicole, L.; Sanchez, C.; Grosso, D. Small 2006, 2, 569-574. doi:10.1002/smll.200500333

13. Schulze, C.; Faustini, M.; Lee, J.; Schletter, H.; Lutz, M. U.; Krone, P.; Gass, M.; Sader, K.; Bleloch, A. L.; Hietschold, M.; Fuger, M.; Suess, D.; Fidler, J.; Wolff, U.; Neu, V.; Grosso, D.; Makarov, D.; Albrecht, M. Nanotechnology 2010, 21, 495701. doi:10.1088/0957-4484/21/49/495701

14. Allouche, J.; Lantiat, D.; Kuemmel, M.; Faustini, M.; Laberty, C.; Chaneac, C.; Tronc, E.; Boissiere, C.; Nicole, L.; Sanchez, C.; Grosso, D. J. Sol-Gel Sci. Technol. 2010, 53, 551-554. doi:10.1007/s10971-009-2130-z

15. Lepoutre, S.; Grosso, D.; Sanchez, C.; Fornasieri, G.; Rivière, E.; Bleuzen, A. Adv. Mater. 2010, 22, 3992-3996. doi:10.1002/adma.200903768

16. Volatron, F.; Heurtaux, D.; Catala, L.; Mathonière, C.; Gloter, A.; Stéphan, O.; Repetto, D.; Clemente-León, M.; Coronado, E.; Mallah, T. Chem. Commun. 2011, 47, 1985-1987. doi:10.1039/c0cc04940a

17. Pajerowski, D. M.; Gardner, J. E.; Frye, F. A.; Andrus, M. J.; Dumont, M. F.; Knowles, E. S.; Meisel, M. W.; Talham, D. R. Chem. Mater. 2011, 23, 3045-3053. doi:10.1021/cm2003337 18. Cobo, S.; Molnár, G.; Carcenac, F.; Szilágyi, P. Á.; Salmon, L.; Vieu, C.; Bousseksou, A. J. Nanosci. Nanotechnol. 2010, 10, 5042-5050. doi:10.1166/jnn.2010.2430

19. Kuemmel, M.; Allouche, J.; Nicole, L.; Boissière, C.; Laberty, C.; Amenitsch, H.; Sanchez, C.; Grosso, D. Chem. Mater. 2007, 19, 3717-3725. doi:10.1021/cm0706245

20. Mutin, P. H.; Guerrero, G.; Vioux, A. C. R. Chim. 2003, 6, 1153-1164. doi:10.1016/j.crci.2003.07.006

21. Guerrero, G.; Mutin, P. H.; Vioux, A. Chem. Mater. 2001, 13, 4367-4373. doi:10.1021/cm001253u

22. Sanchez, C.; Boissière, C.; Grosso, D.; Laberty, C.; Nicole, L. Chem. Mater. 2008, 20, 682-737. doi:10.1021/cm702100t

23. Faustini, M.; Drisko, G. L.; Boissiere, C.; Grosso, D. Scr. Mater. 2014, 74, 13-18. doi:10.1016/j.scriptamat.2013.07.029

24. Faustini, M.; Boissière, C.; Nicole, L.; Grosso, D. Chem. Mater. 2014, 26, 709-723. doi:10.1021/cm402132y

25. Shon, Y.-S.; Gross, S. M.; Dawson, B.; Porter, M.; Murray, R. W. Langmuir 2000, 16, 6555-6561. doi:10.1021/la000329y

26. Pasquinet, E.; Bouvier, C.; Thery-Merland, F.; Hairault, L.; Lebret, B.; Méthivier, C.; Pradier, C. M. J. Colloid Interface Sci. 2004, 272, 21-27. doi:10.1016/j.jcis.2003.11.025

27. Tricard, S.; Raza, Y.; Mazerat, S.; Aissou, K.; Baron, T.; Mallah, T. Dalton Trans. 2013, 42, 8034-8040. doi:10.1039/c3dt50259g

28. Tricard, S.; Fabrice, C.; Mallah, T. Dalton Trans. 2013, 42, 15835-15845. doi:10.1039/c3dt51636a 
29. Nakamoto, K. Infrared and Raman spectra of inorganic and coordination compounds, 4th ed.; Wiley-Interscience: New York, NY, USA, 1986.

30. Bonhommeau, S.; Pontius, N.; Cobo, S.; Salmon, L.;

de Groot, F. M. F.; Molnár, G.; Bousseksou, A.; Durr, H. A.;

Eberhardt, W. Phys. Chem. Chem. Phys. 2008, 10, 5882-5889. doi:10.1039/b806783j

\section{License and Terms}

This is an Open Access article under the terms of the Creative Commons Attribution License

(http://creativecommons.org/licenses/by/2.0), which permits unrestricted use, distribution, and reproduction in any medium, provided the original work is properly cited.

The license is subject to the Beilstein Journal of

Nanotechnology terms and conditions:

(http://www.beilstein-journals.org/bjnano)

The definitive version of this article is the electronic one which can be found at: doi:10.3762/bjnano.5.204 